Fred Thompson

\title{
UTOPIA AND NOSTALGIC RETURN
}

Japan views buildings as events, not simply as inert objects.

A. Isozaki

I would like to base my argument on Thomas Immoos' observation in Japanese theatre that in spite of recent flashes of economic success: "Japanese culture is that of the poor man who has never learned to give anything up, however eagerly he may grasp at anything new. All styles are preserved here with incredible faithfulness. The younger generation displays its loyalty to its heritage by meticulous observance of the forms it has inherited. Thus, even in the course of hundreds of years, only small variations creep in. The idea, the concept, the logos, may well evaporate. But the form remains in petrified mystery."

By this I mean that the form remains Japanese. The content may change because the Japanese often adapt to new realities yet the form will remain Japanese. Rather than get into a complicated argument about the present machinations of contemporary Japanese architects I would like to focus on the intersection of past times with ideal futures to show how, to use James Joyce's words, "past times become pastimes". Three examples come to mind and they are concerned with the resurgence of the dwellings of the common people, known 


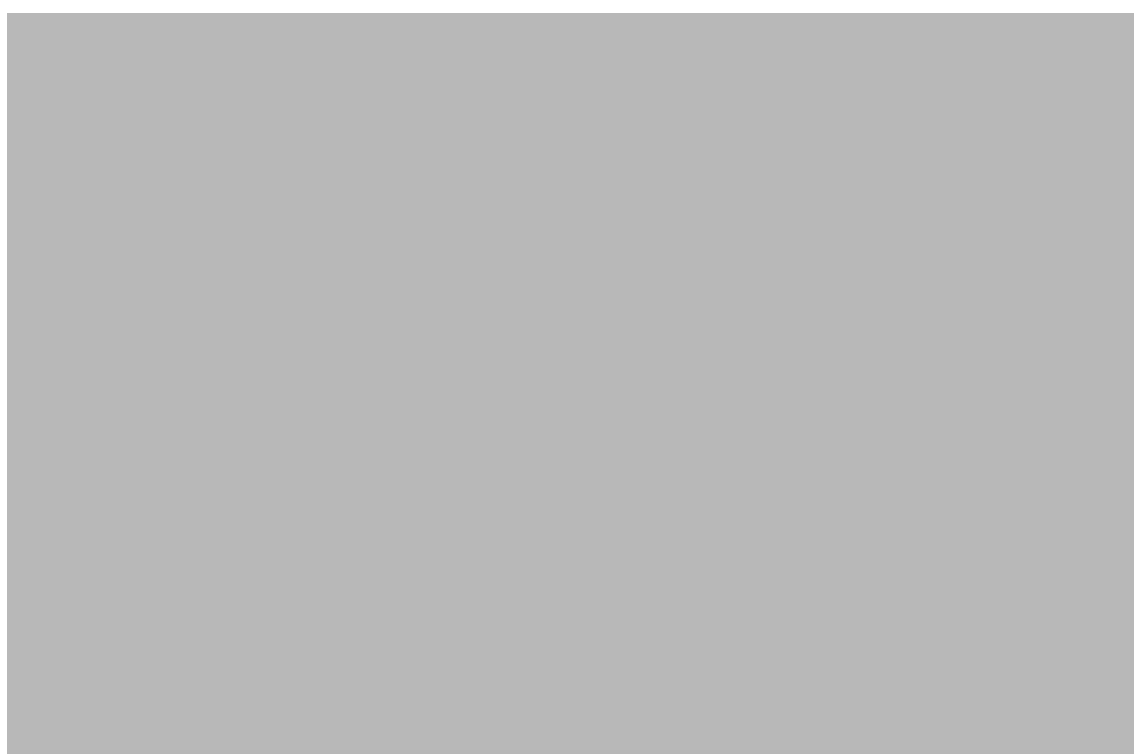

FIG. 1. PIT DWELLING, YAYOI PERIOD, $200 \mathrm{BC}$.

as minka (the people's house) in shapes which are heavily disguised to the untrained eye but which remain true to the spirit of Japanese building.

The first example would be the Tea House, the second the Western and Japanese responses to the $20^{\text {th }}$ century ideal of functionalism, and the third the post war movement known as the Metabolists.

There are many more examples which can be discussed but because of the limits imposed I shall just deal with three to show how the form, as a structure, remains true to the origins of the minka, The house of the farmer and of the common people.

The origins of the minka date back to the pit dwellings (Fig. 1) of the Yayoi period (200 BC). Eventually the pit dwelling was accompanied by a store house on pillars with a platform above the ground, built under a great roof; and over time, to the more common example of minka seen today (Fig. 2).

In Fig. 3 we see a diagram of Mt Fuji, taken from Bruno Taut's Houses and Peoples of Japan (1958), with the shogun (hereditary commander in chief) at the top followed by the daimyo (great lords who were

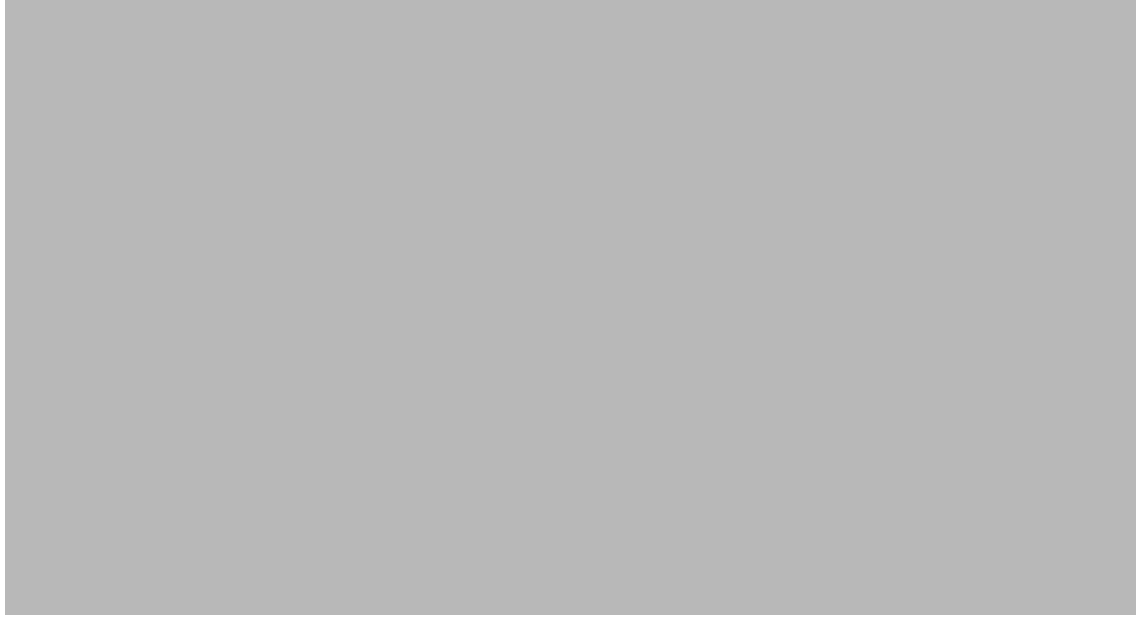

FIG. 2. MINKA: TYPICAL COMMONER'S HOUSE.

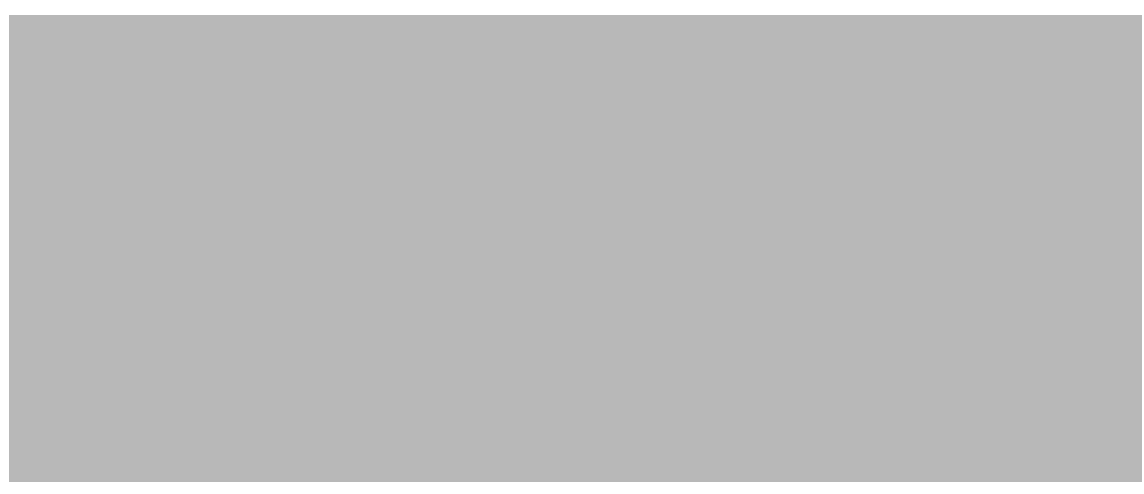

FIG. 3. MT FUJI, REDRAWN SKETCH FROM BRUNO TAUT'S HOUSES AND PEOPLE OF JAPAN (1958).

vassals of the shogun). And under the diamyo come the samurai. At the centre are the commoners, represented in architectural terms by the minka as the base on which Japanese society stands. Underneath the roots of Japanese society lay the mirror image of Mt Fuji with artisans, merchants and performers in descending order. Above Mt Fuji floats a cloud, the emperor, and below in the reflected image the submerged cloud of the untouchables. The Mt Fuji of the shogun, diamyo and samurai becomes top heavy with bureaucracy and power so 


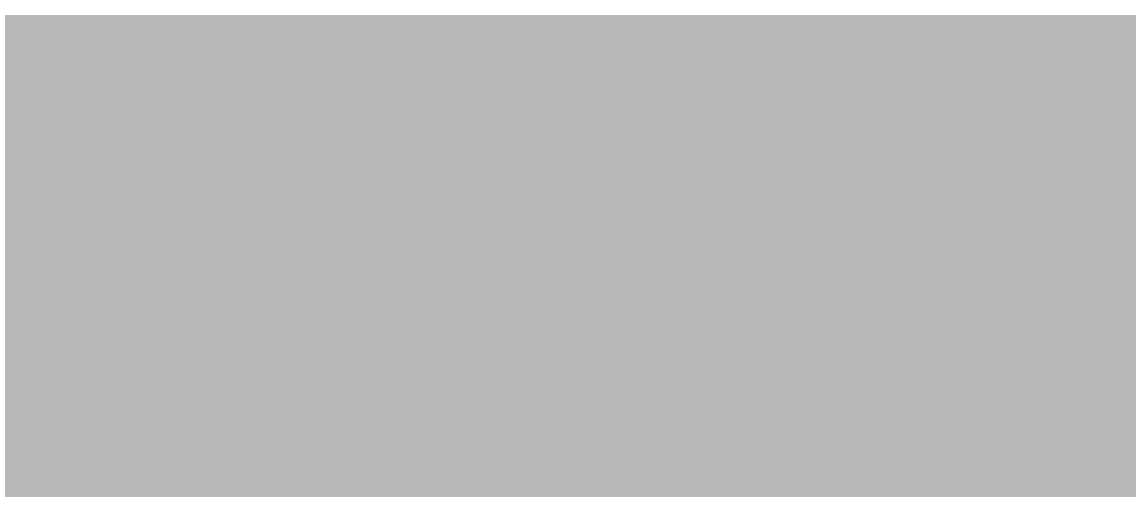

FIG. 4. KAKUNODATE, SAMURAI HOUSE.

that during the Edo period (1600-1800) a layer of artisans, merchants and performers is introduced over the commoners. Only the emperor remains in a cloud above everyone. Put another way, the Tokugawa reign created an unnatural influx of key people to Edo (later Tokyo) from all parts of Japan in order to quell any possibility of dissent. This then exploded when the Meiji restoration (1868) relieved the daimyos of their diplomatic residences in Edo.

This is just one example of an urban population explosion for the purposes of national security, and a subsequent remigration of much of that population back to the countryside. As a result of this Edo-period urban stagnation the residences of the daimyo and samurai became more lavish and monumental, as can be seen in Fig. 4. There were several such instances of population movement in Japanese history.

The introduction of Buddhism in the sixth century had a centralising effect on Japanese culture and architecture, as did the effects of the ruling class of the Kamakura period of the $12^{\text {th }}$ century. During the Momoyama period of the $16^{\text {th }}$ century Japan's great castles were built as were their counterpart, the most humble of all buildings, the Japanese Tea House, which recalled the roots of Japanese architecture to the souls of even the most flamboyant of the war lords.

The minka remain a form of anonymous building. Commoners were poor, extremely poor, and in many instances farms were managed by women because there was limited food for large families and the men had to leave to find other work after the farming season. This supplementary labour saw the men working in construction as stone masons, framing carpenters, finish carpenters, roofers, etc. These wandering labourers were a means by which isolated hamlets learnt of each other's existence, and customs as well as building techniques were passed from community to community. It is said that in some places where there was no work to be had, the wandering carpenters were given pair of straw sandals as a form of compensation so that that they could continue their wandering in search of work. The best of these carpenters came from a region around the present city of Takayama and were known as Hida no Takumi. Instead of paying taxes to the central government in Kyoto in the form of rice, they were known for paying it in the form of labour and as a result many of Kyoto's finest temple, shrines and administrative buildings were built by the carpenters of Takayama. Two examples of their minka in Takayama itself are the Yoshijima house and the Kusakabe house (Fig. 5).

In principle, the minka is made up of two parts: a principle structure and a secondary structure, with a different type of carpenter for each. In most cases, the principle structure was raised and roofed by a large team of carpenters and left to the inhabitants in that form, rather like a Mennonite barn raising, so that the inhabitant could carry on with the secondary structure and furnishings at a later time that suited their economic situation.

The primary structure was known as the jikugumi and the secondary structure as the zosaku (or fittings). Simply put, the jikugumi held up the great roof and the zosaku consisted of the non-structural elements, which if removed or replaced would not cause a collapse of the building. It is this principle of primary and secondary structures that dominates attitudes towards form in Japanese architecture, something that is the result of the climate, geography, culture and above all, simple and essential needs of the common people. To go one step further, it should be said that while the non-Asian world would tend to look at Japanese buildings from the view point of their facades, the Japanese have traditionally seen them in the form of a structure. Houses were planned two dimensionally, with dots for the pillars on a simple plan board. There were no drawings of sections or of the facade. In their place were two sets of measuring rods 


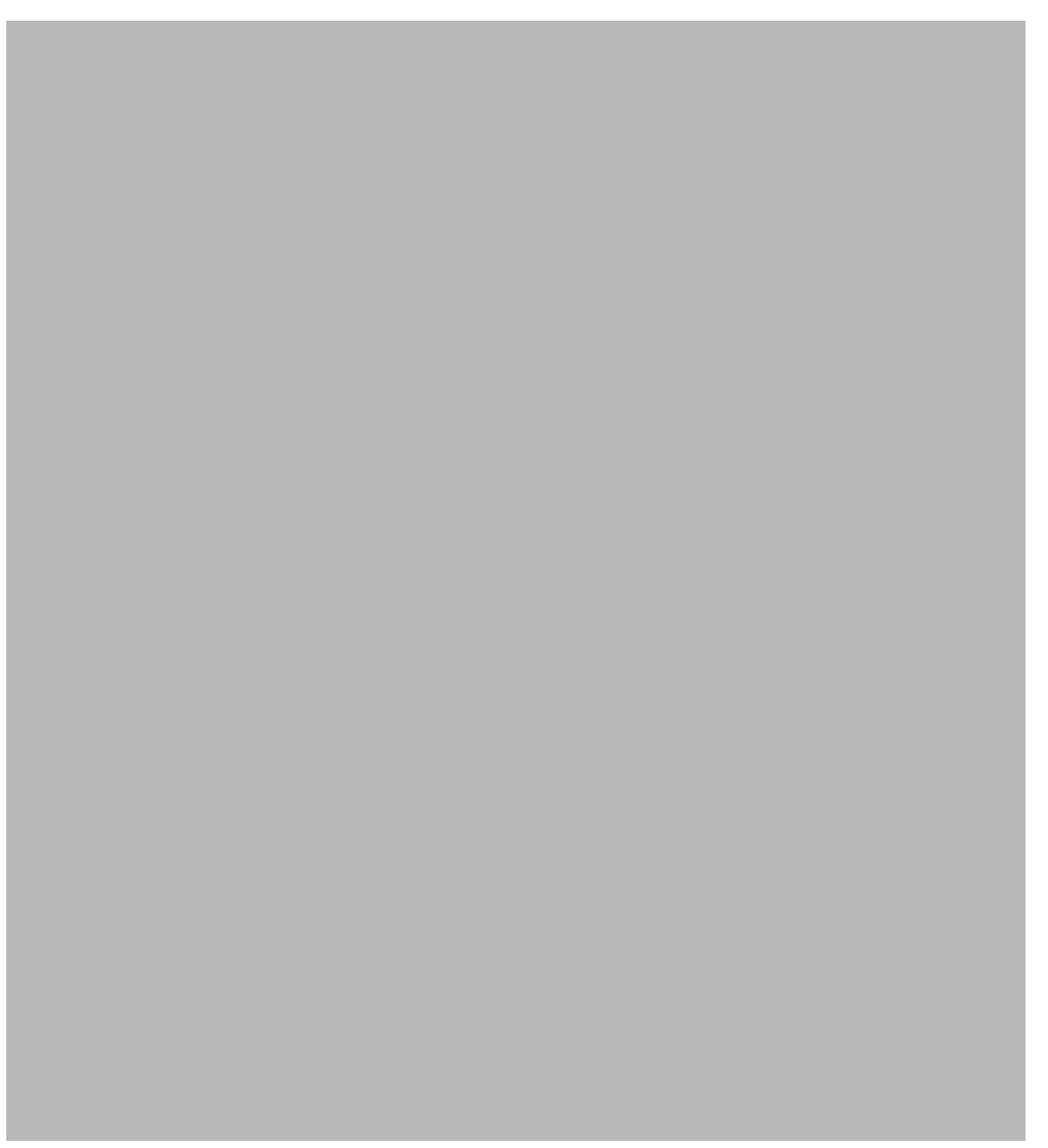

FIG. 5. YOSHIJIMA HOUSE, TAKAYAMA CITY: INTERIOR SHOWING ROOF STRUCTURE.

marked off in proportions used by the secondary team carpenters to make sliding panels, doors, partitions screens and other pieces of zosaku. Proportions, in the form of measuring rods, determined what the building would look like. And these measuring rods remained with the building so that seasonal doors and screens could be made to harmonise with the structure. Fig. 6 shows the disassembly of a building so that when all the zosaku are removed, only the structure, the jikugumi, remains. 
Over time, and with the waxing and waning of the population the minka drops further and further into the background. Building, first of great temples and residences for the emperor, began to take precedence from the sixth century onwards. Styles such as the shoin and tsukiya became very popular, but it was during the period of greatest affluence and decadence that the humble building of the tea house recovers the spirit of the minka.

There is a story told of a merchant who was selling ceramics at a weekly market. The bottles were not very attractive so somebody asked the merchant why he chose to try to sell his wares. The merchant replied that "inside the ugly bottle there is beauty. Don't judge it from the outside".

The tea house is made up of principle and secondary parts, just like the minka, but in a flimsy manner with utmost attention to detail. The materials used for the tea house are of the most rudimentary nature often using scrap material in what today might be called a form of re-cycling. Unfinished wood, river bed clay and cheap forms of thatch all contributed to the humble nature of the place. Most humbling was often the entrance, which was usually small square door of $3^{\prime} \times 3^{\prime}$. The restricted size meant that to enter, the guest, often a samurai, would have to remove his sword and lower his head in order to enter a small sparsely decorated room for a cup of tea. The tea house therefore becomes one of the first real recollections of the roots of Japanese architecture, the humble abode of the peasant.

The main difference between the minka and the tea house is that the minka is built of pillars with sliding doors so that there is no substantial difference between inside and outside. Layers of doors and screens are added in the winter, and removed in summer. The tea house, on the other hand, was cut off from the outside. Of course there were windows but they were usually only for the purpose letting light into the room, not for seeing out. (Fig. 7) The guest was left to concentrate on a vase with a simple flower arrangement, a scroll of calligraphy to compliment it and a cup of green tea. Thus the spirit of the form, although humbler in its scale and with greater attention to detail, remained the same (while the content changed).

A second recovery of the minka aesthetic came in the 1920s and 1930s with the introduction of 'functionalism' in Europe, and in particular through the writings of Bruno Taut, from Germany. Taut had been overwhelmed by the sophisticated simplicity of the Katsura

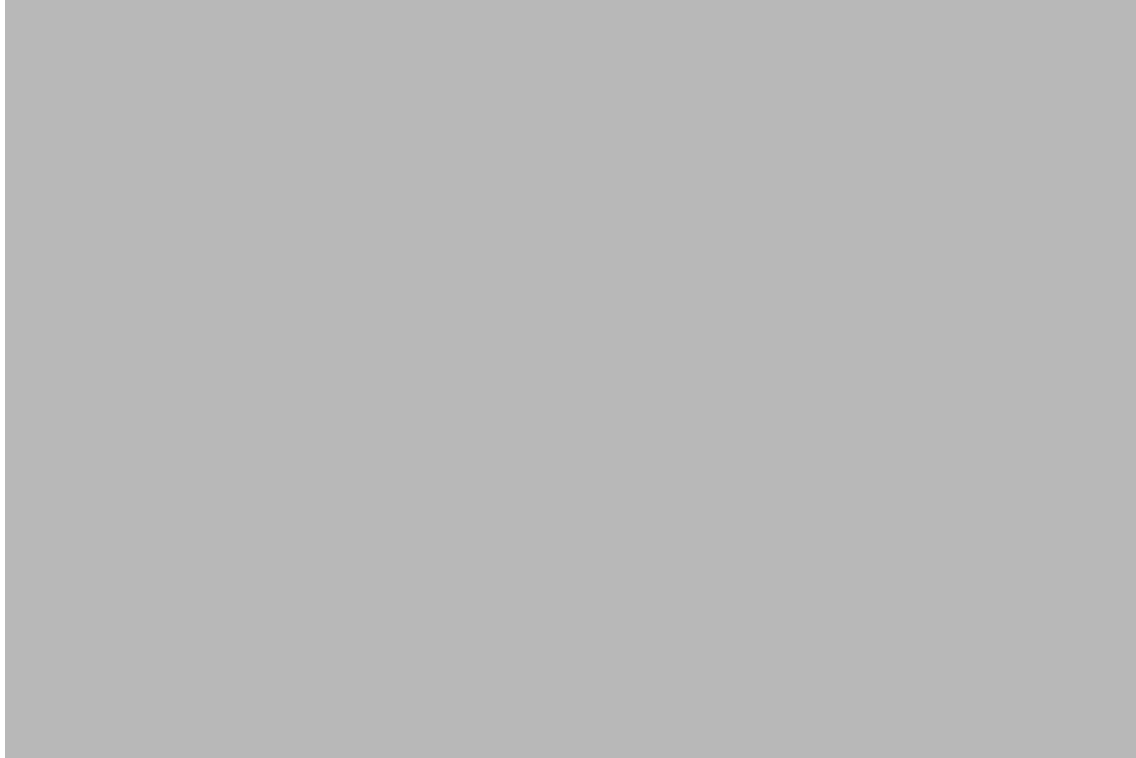

FIG. 7. TEA HOUSE SHOWING EFFECT OF WINDOWS AS SOURCES OF ILLUMINATION ONLY.

Summer Palace in Kyoto and wrote about how close Katsura was to the spirit of the new age of European architecture, then striving to find a dignified sense of space for the working class. He was also very critical of the Nikko Shrine buildings as being baroque and gaudy. The appeal of the Katsura palace, which had its roots in the minka, fitted in with the less is more ethos (Fig. 8).

The palace was admired for its Mondrian-like proportioning of the facade and its interior freedom from fixed walls so to allow for a more varied use of small spaces. A type of interior space which, in Europe, could accommodate the electric stove and the refrigerator bent steel furniture, etc.

Japan became Shangri-la for Western architects from Europe and America. Little knowledge was gained, and little concern taken, about the fact that at the same time, the Japanese in an effort to become more 'Western' after the Meiji Restoration (1868) were tearing down some of their buildings to replace them with Western architecture. Fortunately most of the minka were too remote to have suffered destruction. 


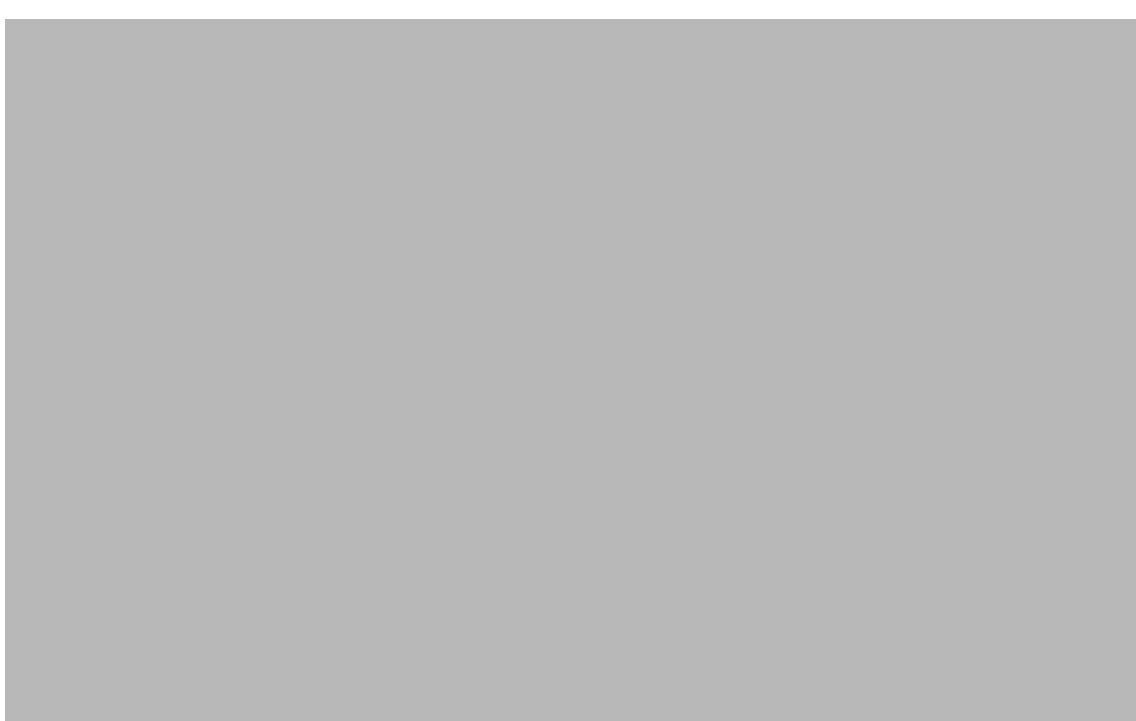

FIG. 8. KATSURA SUMMER PALACE, AN ICON OF ‘TRADITIONAL’ JAPANESE ARCHITECTURE FROM THE 1950S

A third iteration of the minka came with the introduction of Metabolism in the post-war period of the 1950s and 1960s, with the World Design Conference of 1960 showing Japan's 'coming of age'.

Close examination of the minka and of most Japanese architecture, with the possible exception of the pagoda, shows an overwhelming sense of horizontality. Now the central theme of Metabolist architecture was in the Utopian ideal of architecture flying skyward rather than being earthbound. The ideogram for fudo 'man and place' is made up of two Chinese symbols for 'wind' and 'earth', implying the horizontality of the wind and the gravitational force of the earth. The epitome of this period was Kiyonori Kikutake's Sky House (Fig. 9) - the sky as a place to dwell - which used, as Itoh Teiji points out, the minka form jikugumi and zosaku, albeit in high-tech materials.

The Sky House was built on the principle of four pillars, slabs of concrete in this case, holding up a roof of eight concrete hyperbolic curves moulded into a single form resting on the four pillars. A floating slab suspended between the pillars under the roof provides the living space for the family. The living spaces are determined by

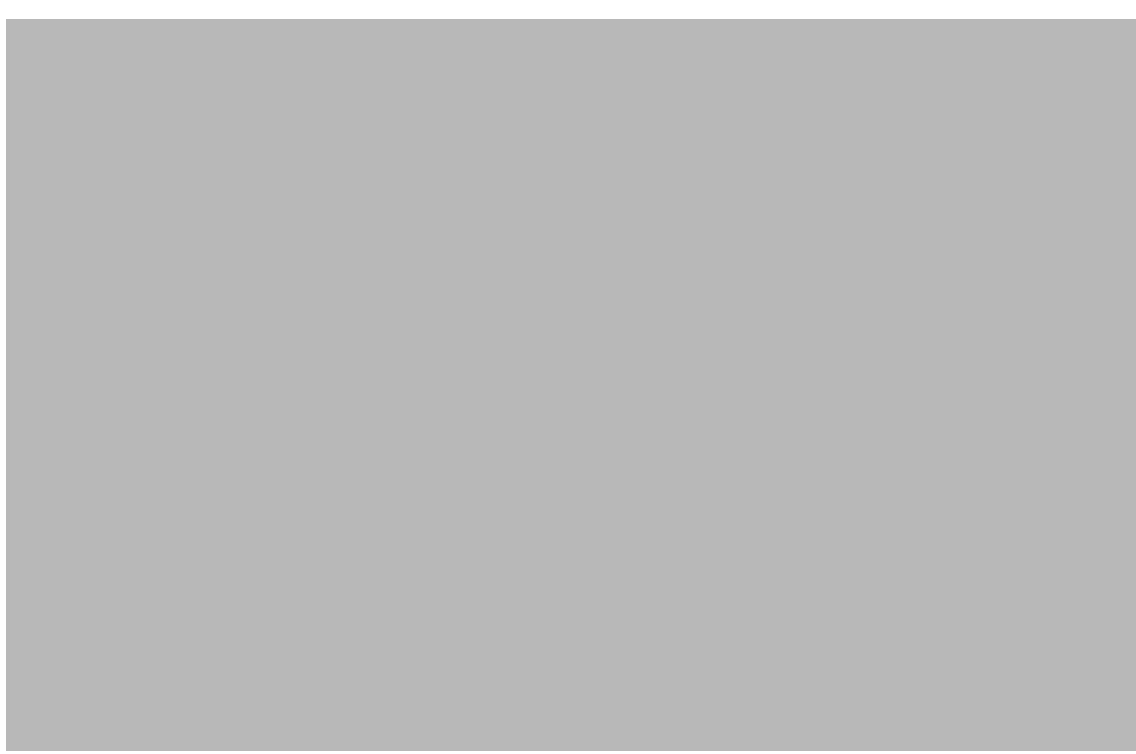

FIG. 9. SKY HOUSE, RESIDENCE OF KIYONORI KIKUTAKE IN TOKYO, 1958

the location of the 'movenettes', prefabricated kitchen and bathroom units. These can be plugged in to a servicing system, or zosaku, that runs around the inner perimeter of the house in the form of a threshold. A variety of options can be seen in Fig. 10.

Form then becomes "space plus function", in the words Kikutake. Spaces in Japan are often described by area, for example 'a six mat room', a '10 mat room', a '4 1/2 mat room', meaning these spaces could be furnished for a bedroom, a dining room or a living room respectively. In the West we tend to talk of a 'dining room' or a 'bedroom', with the form following the function. Japanese rooms, like those of the minka, are usually open to suggestion. In the West this can be compared with the modernist mantra that form follows function, i.e. that the form of a room dictates its function.

Metabolism met its demise with the Utopian ideals of building cities in the ocean (Fig. 11). The source of this idea came from the observation that the Japanese economy was based on the import of raw materials and the export of finished products. Little raw material came from the land itself. This coupled with the observation that 

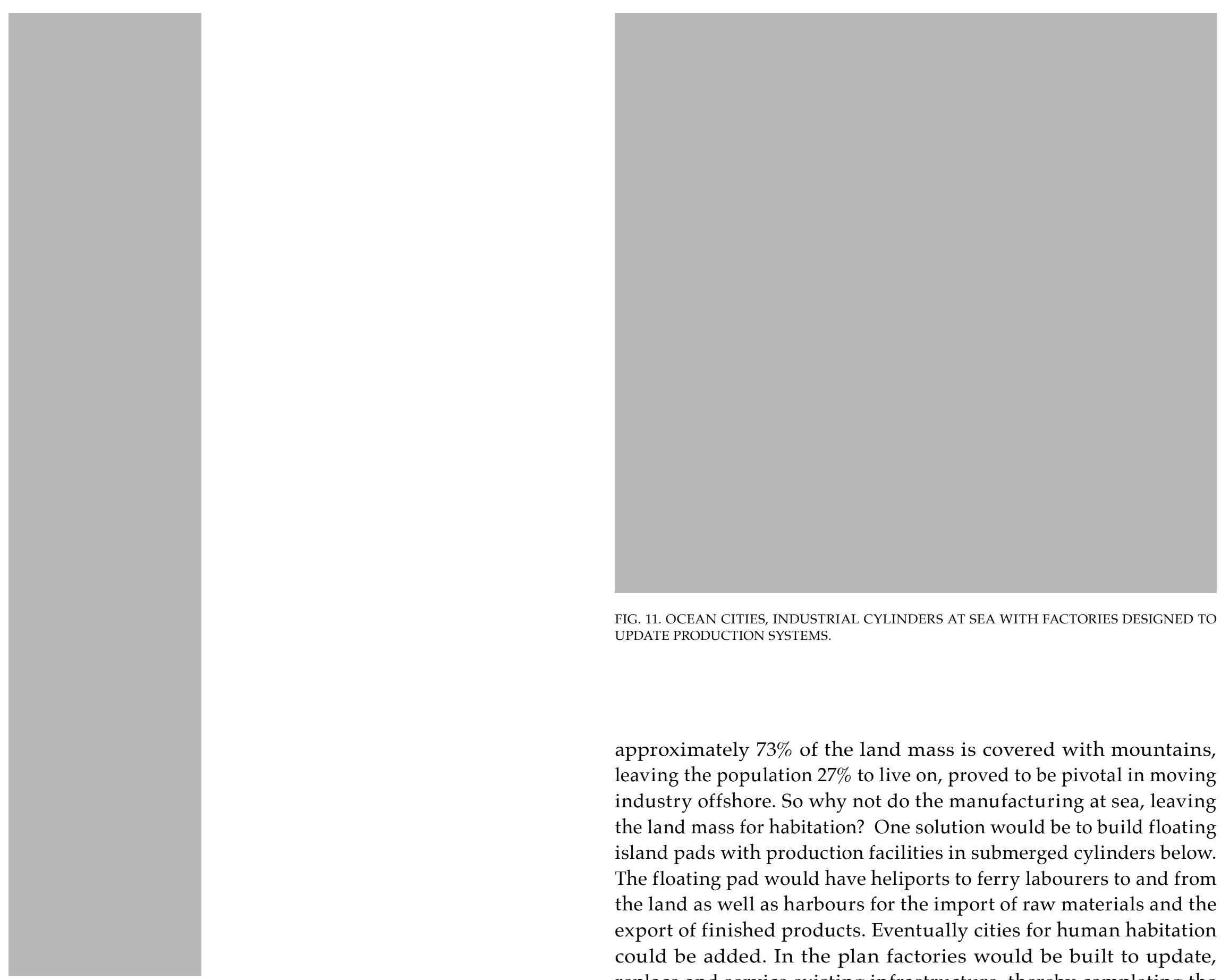

FIG. 11. OCEAN CITIES, INDUSTRIAL CYLINDERS AT SEA WITH FACTORIES DESIGNED TO UPDATE PRODUCTION SYSTEMS

approximately $73 \%$ of the land mass is covered with mountains, leaving the population $27 \%$ to live on, proved to be pivotal in moving industry offshore. So why not do the manufacturing at sea, leaving the land mass for habitation? One solution would be to build floating island pads with production facilities in submerged cylinders below. The floating pad would have heliports to ferry labourers to and from the land as well as harbours for the import of raw materials and the export of finished products. Eventually cities for human habitation could be added. In the plan factories would be built to update, replace and service existing infrastructure, thereby completing the 
for the cities themselves. The only example of this Utopian form to reach fruition was an exhibition platform at sea in Okinawa in 1975 known as Aquapolis.

As a post script it can be observed that in architectural journals at the turn of the $21^{\text {st }}$ century, architects were preoccupied with designs for small one-family dwellings, and that there was a marked proliferation of books on minka. In addition, through the evolution of Japanese architecture form has remained consistent. Technology has changed, the cultural pressures of wealth and authority have evolved, but form endures. This leads one to believe that in Japan, space plus function (jikugumi plus zosaku) equals form. Take away the structure, be it grammar with language or physical structure with building, and the form dissolves.

Clay is fired to make a pot. The pot's use comes from its emptiness.

Fred Thompson: Utopia and Nostalgic Return

Keywords: Japan; tradition; architecture; Structure; COMMONERS; RENEWAL; MINKA

\section{SUMMARY}

The term 'traditional Japanese architecture' often causes confusion because people want the architecture of a certain period to either continue endlessly, or to be substituted by some kind of facsimile. This paper maintains that the roots of Japanese architecture continue and that these roots make themselves evident at times of upheaval and renewal.

Japan consists of a number islands which have had periods of isolation both internationally, and nationally from 'political lockdown' within. And yet these periods of isolation have often produced a veritable zenith in the houses of what Bruno Taut called "the peasants", and the author has chosen to call 'commoners (minka)'. One example this is the Japanese tea house, which came about at a time of heightened military dominance. Castles were the strongholds of power complete with large rooms in which the rituals of state demanded order by rank. Beside this show of power came the humble tea house, used for the simple tea ceremony, sometimes between as few as two people. The roots of this humble hut, if we can call it such, carried with it the same structural principles as the minka, or commoner's house. A non-loadbearing structure of post and lintel construction for the sole purpose of concentrating on "the sound of boiling water". Out of the dream of power came the need for humility. The warrior's power lay in the control of space; the tea master's in the control of time. The architecture responds. The building is an event.

CV

Fred Thompson is Professor Emeritus of Architecture at the University of Waterloo, Canada. He has made an extnsive study of the relationship between ritual and space, particularly in Japanese culture, and the relation of these issues in Japanese culture and Western ideas of space. In addition he has published Ritual and Space (1988) and a pivotal thesis titled A Comparison between Japanese Exterior Space and Western Commonplace (1988). In addition, he has been a visiting professor at various schools of architecture, including the Helsinki University of Technology, Finland; Columbia University Graduate School of Architecture, Planning and Preservation, New York, USA; the Royal Institute of Technology, Stockholm, Sweden the University of Lund, School of Architecture and Design, Sweden and the Danish Academy of Fine Arts, Copenhagen, Denmark. 
